\title{
A New Genus of the Actinomycetales: Micropolyspora gen. nov.
}

\author{
By H. A. LECHEVALIER AND M. SOLOTOROVSKY \\ Institute of Microbiology and Department of Bacteriology, Rutgers, \\ The State University, New Brunswick, Nerw Jersey, U.S.A. \\ AND CAROLYN I. McDURMONT \\ Department of Public Health, Montgomery, Alabama, U.S.A.
}

(Received 18 April 1961)

\begin{abstract}
SUMMARY
Three filamentous micro-organisms are described. They are typical Actinomycetales forming branching hyphae, $\mathbf{1 . 5} \mu$ or less in diameter, which are differentiated into a substrate (primary) mycelium and an aerial (secondary) mycelium. They have an unusual mode of sporulation since they form chains of conidia both on the substrate and on the aerial mycelium. A new genus, Micropolyspora, is proposed. The type species is $M$. brevicatena. The new genus is part of the family Actinomycetaceae. The abolition of the family Streptomycetaceae is proposed.
\end{abstract}

\section{INTRODUCTION}

Actinomycetes are filamentous bacteria which are often considered as intermediate between the true bacteria and the fungi. According to the latest edition of Bergey's Manual (1957) these organisms are grouped under the order Actinomycetales, which is subdivided into four families as follows:

I. Mycelium rudimentary or absent; no spores formed

Mycobacteriaceae

II. True mycelium produced

A. Spores formed, but not in sporangia

1. Spores formed by fragmentation of mycelium

Actinomycetaceae

2. Vegetative mycelium normally remains undivided

B. Spores formed in sporangia

Streptomycetaceae Actinoplanaceae

Bergey's Manual recognizes three genera in the family Streptomycetaceae.

They are characterized as follows:

I. Conidia produced in aerial hyphae in chains

II. Conidia produced terminally and singly on short sporophores

A. No growth between $50^{\circ}$ and $65^{\circ}$

B. Growth occurs between $50^{\circ}$ and $65^{\circ}$

Streptomyces

Micromonospora

Thermoactinomyces

Since the publication of the 1957 edition of Bergey's Manual, other genera have been described, to include organisms which have novel modes of spore formation. These include: (1) Waksmania Lechevalier \& Lechevalier (1957), in which pairs of spores are formed longitudinally on the aerial mycelium. The same genus, under the name Microbispora, was described at the same time in Japan by Nonomura \& 
Ohara (1957). (2) Thermopolyspora, in which short chains of spores are formed on the aerial mycelium of thermophilic organisms (Henssen, 1957).

The present paper reports the isolation and description of a type of actinomycete which produces spore-bearing substrate mycelia and aerial mycelia. The name proposed for the new genus is Micropolyspora. The type species is M. brevicatena. Two strains have been isolated and are deposited in the culture collection of the Institute of Microbiology, Rutgers, The State University, New Brunswick, N.J. (nos. 1084 and 1086). In addition another strain of the same genus was also isolated (no. 1085). This strain has cultural properties which differentiate it from the other two. Until more strains of this new genus are isolated and studied we shall refer to this culture as Micropolyspora sp. no. 1085.

\section{METHODS}

Isolation. Specimens of sputa taken in routine examination for Mycobacterium tuberculosis var. hominis were treated with $4 \%(\mathrm{w} / \mathrm{v}) \mathrm{NaOH}$ and shaken on a mechanical shaker for $10 \mathrm{~min}$. After neutralization with $2 \mathrm{~N}$-hydrochloric acid, the suspensions were centrifuged and the sediment used to inoculate two tubes of a Jensen-Holm modification of Lowenstein medium (American Public Health Association, 1950) and two tubes of penicillin blood agar (Tarshis, 1953). The tubes were incubated at $37^{\circ}$, horizontally for the first $72 \mathrm{hr}$. and then upright. They were examined weekly after the first 2 weeks.

Stains. Acid-fast staining was essentially as described on page 229 of Staining Procedures used by the Biological Stain Commission (Conn, Darrow \& Emmel, 1960) except that one drop of Tergitol No. 7 (Carbide \& Carbon Chemical Co., 30 East 42nd St., New York, N.Y.) was added to 30-40 ml. of carbol fuchsin just before staining. The Gram stains were done by covering smears for $1 \mathrm{~min}$. with a $1 \%(\mathrm{w} / \mathrm{v})$ aqueous solution of crystal violet and adding simultaneously five drops of $5 \%(\mathrm{w} / \mathrm{v})$ aqueous sodium bicarbonate. After drainage, the slides were covered for $1 \mathrm{~min}$. with an aqueous solution containing $2 \%(\mathrm{w} / \mathrm{v})$ potassium iodide and $1 \%$ $(\mathrm{w} / \mathrm{v})$ mercury potassium iodide. After washing with water, the smears were decolorized with acetone, rinsed with water and stained for one minute with a $0 \cdot 1 \%(\mathrm{w} / \mathrm{v})$ aqueous solution of safranin $\mathrm{Y}$.

Media. The composition of all media not listed here, and for which there are no references given in the text, will be found in the appendix of Waksman (1950) or in the Difco Manual (1953).

NZ-amine glycerol agar. NZ-amine A (casein hydrolysate; Sheffield Farms; 1267 6th Ave., New York), 5 g.; beef extract, 1 g.; glycerol, 70 ml.; agar, 15 g.; tap water, 1 1.; $\mathrm{pH} \mathrm{6 \cdot 5-7 \cdot 0.}$

Nutrient agar with glucose. Nutrient agar with $1 \%(\mathrm{w} / \mathrm{v})$ glucose.

Nutrient agar with glycerol. Nutrient agar with $70 \mathrm{ml}$. glycerol/l.

Soil extract glycerol agar. Peptone, $5 \mathrm{~g}$.; beef extract, $3 \mathrm{~g}$.; agar, $15 \mathrm{~g}$.; soil extract, $250 \mathrm{ml}$.; tap water to 1 1.; $\mathrm{pH} 6 \cdot 5-7 \cdot 0$. Soil extract was prepared by autoclaving $1 \mathrm{~kg}$. air-dried garden soil with $2 \cdot 4 \mathrm{l}$. tap water for $1 \mathrm{hr}$. at $121^{\circ}$, filtering through paper and autoclaving for storage.

Defined medium. Glycerol, $70 \mathrm{ml}$;; L-glutamic acid, $1.5 \mathrm{~g} . ; \quad$ L-arginine, 1.0 g.; $\mathrm{K}_{2} \mathrm{HPO}_{4}, 1.0$ g.; $\mathrm{MgSO}_{4} .7 \mathrm{H}_{2} \mathrm{O}, 100 \mathrm{mg}$.; $\mathrm{CaCl}_{2}, 10 \mathrm{mg}$.; $\mathrm{ZnSO}_{4}, 10 \mathrm{mg}$.; $\mathrm{Fe}_{2}\left(\mathrm{SO}_{4}\right)_{3} .9 \mathrm{H}_{2} \mathrm{O}, 10 \mathrm{mg}$; agar, $15 \mathrm{~g}$.; distilled water, $1 \mathrm{l}$; $\mathrm{pH} 6 \cdot 5$ to $7 \cdot 0$. 
Photographs. Microphotographs were taken through a trinocular American Optical 'Microstar' Microscope with a $35 \mathrm{~mm}$. photomicrography attachment. Kodak High Contrast Copy film was used. All microphotographs except Pl. 1, fig. 8, are of undisturbed plate cultures. Microphotographs were taken in situ through $\times 40$ or $\times 57$ achromatic objectives. The microscope was equipped with a long focus condenser which gave adequate lighting even through thick layers of agar. Plate 1, fig. 8, was taken through a $\times 93$ fluorite objective.

Electron photomicrographs (Pl. 1, figs. 6, 7) were taken with an RCA EMU-1 electron microscope modified with Canalco equipment. Collodion films mounted on grids were touched to the surface of 5-day cultures grown at $37^{\circ}$ on $\mathrm{N}-\mathrm{Z}$ amine glycerol agar, portions of the mycelium becoming attached to the collodion membrane. The materials were not shadowed.

Examination of spore germination. Agar blocks from well-sporulating $\mathrm{N}-\mathrm{Z}$ amine glycerol agar plate cultures were cut out aseptically and placed on sterile glass slides on the stage of a microscope. Spores were teased off the mycelium and spread over sterile portions of the agar blocks with a $5 \mu$ sterile glass microhook, manoeuvred with a Cailloux micromanipulator. Slides were incubated in a humid chamber at $37^{\circ}$ and examined periodically under the microscope. The number of germ tubes was counted after incubation for $18 \mathrm{hr}$.

\section{RESULTS}

\section{Description of Micropolyspora Lechevalier, Solotorovsky and McDurmont, gen. nov.}

Morphology. Fine mycelium (about $1 \mu$ in diam.) which is differentiated into: (1) a substrate (primary) mycelium which grows into and forms a compact layer on top of agar media; (2) an aerial (secondary) mycelium which arises from the substrate mycelium and grows in the air away from the agar surface. Both the substrate hyphae and the aerial hyphae bear chains of conidia which are produced either directly on the mycelium or on sporophores which branch from the mycelium. Three strains were isolated: no. 1084, 1085 and 1086. The type species is based on the properties of no. 1084 and 1086 . Isolate 1085 , which is morphologically similar, has different cultural properties as indicated below.

Type species, Micropolyspora brevicatena, Lechevalier, Solotorovsky and McDurmont, sp.nov.

Substrate mycelium. About $1 \mu$ in diameter. Filaments long, branching, penetrating the agar medium and forming compact colonies which are at first whitish on most media and become yellowish. Single spores or short chains of spores ( 2 to 10 ) are formed in the agar (Pl. 1, fig. 3) and on the surface of the agar where they are most easily observed (Pl. 1, figs. 1, 2).

Aerial mycelium. About $1 \mu$ in diameter. Long branching hyphae, not abundant on most media. Short chains of spores formed (Pl. 1, figs. 4, 5). Often aerial hyphae will bend back in the agar after having grown in the air, forming solon-like structures (Pl. 1, fig. 9). Aerial hyphae will often aggregate to form long multi-filamentous strands which may link adjoining colonies. The tip of an aerial hypha, in young growing cultures, often curls up into a globose structure which is formed by the 
tightly coiled filament (Pl. 1, fig. 4). These bodies have been observed to uncoil suddenly, with the resulting formation of a stolon. This sudden uncoiling was reminiscent of the casting of a fisherman's line.

Dome-shaped bodies. Hyphae often aggregate in a tough matty pseudo-tissue, which eventually forms a dome on the surface of the agar. Cutting through the cover of the dome reveals a hyaline gel which is rich in spores.

Spores. Spherical to oblong, sometimes pyriform, about $1.5 \mu$ in diameter. Spores are borne terminally on sporophores (Pl. 1, fig. 7) which are sometimes branched (Pl. 1, fig. 6), as well as at the tip of main hyphae. They are also borne sessile on the side of hyphae. Spores are formed singly or in short chains (2 to 10 spores) and are most abundant and most easily observed on the surface of the agar. Isolate 1086 forms straight chains of spores, whereas the chains are slightly coiled or wavy in isolate 1084 (Pl. 1 figs. 1, 2). Spores are easily separated one from the other, but often stay and germinate in pairs. During germination, one to three germ tubes are formed. An incubation period of 5 to 7 days at $37^{\circ}$ was optimal for the observation of the spores on the NZ-amine glycerol medium. The surface of the spores is very slightly warty (Pl. 1, figs. 6, 7).

Spore formation. A bud on a hypha grows to form a small branch, near the tip of which one septum appears; while the branch is still growing, a second septum is formed, then a third, etc. (Pl. 1, figs. 10, 11). The cells which have been walled off swell slightly, so that the spores are of a somewhat larger diameter than the hyphae, as indicated above (Pl. 1 , figs. 3, 6, 7, 8). The mode of formation of the conidia is typically fungal in nature and is of the type illustrated in Fig. 251 A of Langeron \& Vanbreuseghem (1952).

Fragmentation. Even though fragmentation is not apparent during the in situ examination of the mycelium, either with bright field or phase contrast microscopy, the mycelium is easily separated into numerous fragments in the process of making smears.

Diffusible pigments. Isolate 1084 forms a light brown pigment after prolonged incubation (2 weeks) on certain media, such as NZ-amine glycerol agar. Isolates 1085 and 1086, in our studies, did not form any diffusible pigment.

Appearance on various media. All cultures were incubated for 2 weeks at $37^{\circ}$. No growth took place on the following media: starch agar A, starch agar B, glucose asparagine agar, Czapek agar. In addition, no growth occurred in nitrate broth, carbon-free cellulose medium, or oatmeal agar (Lechevalier \& Lechevalier, 1957).

Yeast extract agar. Isolate 1084: thin growth with powdery surface; pale orange (Séguy 200). Isolates 1085 and 1086: thin growth with powdery surface; pale orange-yellow (Séguy 250).

Rice-extract agar and Pablum-extract agar (Lechevalier \& Lechevalier, 1957). Isolates 1084 and 1086: very little growth, powdery white. Isolate 1085 : powdery white with a few light orange spots.

Potato plug. Isolate 1084: thin powdery growth, centre pale mauve (Séguy 239), edge pale orange-mauve (Séguy 180). Isolates 1085 and 1086: scarce thin powdery growth, pale mauve (Séguy 5).

NZ-amine glycerol agar. Isolate 1084: abundant, slightly wrinkled growth, pale orange (Séguy 200). Isolates 1085 and 1086: same as isolate 1084; pale orangeyellow (Séguy 250). 
Defined medium. Isolate 1084: growth less abundant than on NZ-amine glycerol agar, pale orange (Séguy 199), white powdery surface. Isolate 1086: same, as 1084 pale orange-yellow (Séguy 250). Isolate 1085: no growth.

Nutrient agar. Isolate 1084: scarce, thin, buff growth. Isolate 1086: scarce, thin colourless growth. Isolate 1085: scarce, thin white growth.

Nutrient agar with glucose. Isolate 1084: powdery growth, thicker than on yeast extract agar, pale orange (Séguy 190). Isolate 1086: growth pale orange (Séguy 190) with a powdery white surface. Isolate 1085: thin powdery growth, pale orangeyellow (Séguy 250).

Nutrient agar with glycerol. Isolates 1084 and 1086: thick, shallowly wrinkled growth, pale orange-yellow (Séguy 249). Isolate 1085: thin powdery growth, pale orange-yellow (Séguy 250).

Litmus milk. Isolate 1084: slight powdery white pellicle, no effect on milk. Isolates 1085 and 1086: no growth.

Effect of $p H$ and temperature on growth. Yeast-extract agar slopes were prepared at four different $\mathrm{pH}$ values $(5 \cdot 1,6 \cdot 3,7 \cdot 4,8 \cdot 4)$, inoculated with isolates 1084,1085 and 1086, and incubated at $28^{\circ}, 36^{\circ}$ and $50^{\circ}$. Growth was best at $\mathrm{pH} 6.3$ and $36^{\circ}$. No growth took place on any medium at $50^{\circ}$. No growth took place at pH $5 \cdot 1$ at any temperature.

Oxygen requirement. No growth took place on soil extract glycerol agar under a nitrogen atmosphere, or when the pyrogallol method (Fred \& Waksman, 1928) of removing oxygen was used. Control aerobic cultures grew abundantly.

Defined medium for growth. In the presence of glucose, sucrose or glycerol, the following inorganic sources of nitrogen did not permit growth: $\mathrm{NH}_{4} \mathrm{NO}_{3}, \mathrm{NaNO}_{3}$, $\left(\mathrm{NH}_{4}\right)_{2} \mathrm{SO}_{4}$. In presence of glycerol, DL-asparagine and DL-aspartic acid hardly permitted any growth, but L-glutamic acid was a good source of nitrogen for growth, even though sporulation was not abundant. Sporulation of isolates 1084 and 1086 was stimulated by L-arginine, which by itself was not satisfactory for growth and which prevented the growth of isolate 1085 in presence of L-glutamic acid. Good growth and sporulation of isolates 1084 and 1086 were obtained when magnesium sulphate, potassium phosphate, and calcium chloride were added to the $\mathrm{L}$-arginine $\mathrm{L}_{\mathrm{L}}$ glutamic acid + glycerol mixture. The addition of iron and zinc was not essential in this medium, which was obviously grossly contaminated with trace elements (see composition of the medium under METHODs).

Staining properties. The staining properties did not vary with the age of the culture (between 2 weeks and 2 months), but there was variation from one medium to another. On Lowenstein's and penicillin blood agar about $75 \%$ of the organisms on smears were acid-fast, whereas on Sabouraud glucose and yeast-extract agar about $30 \%$. Less variation was observed with the Gram reaction, both organisms being about $\mathbf{5 0} \%$ Gram-positive on all media.

Antibiotic properties. No activity by cross-streak test (Waksman, 1950) on yeastextract glucose agar against Aspergillus niger 13, Mucor rouxii 80, Candida albicans 204, Saccharomyces cerevisiae 216, Bacillus cereus 8, Escherichia coli 54, or Sarcina lutea 14.

Sensitivity to antibiotics and antimicrobial agents. On yeast-extract agar, isolates 1084, 1085 and 1086 grew in the presence of pure candidin, $80 \%$ pure candicidin, and pure cycloheximide at $100 \mu \mathrm{g} . / \mathrm{ml}$. Streptomycin at $100 \mu \mathrm{g} . / \mathrm{ml}$. inhibited 
completely the growth of these isolates; chloramphenicol or neomycin at $5 \mu \mathrm{g} . / \mathrm{ml}$. had the same effect. Neomycin at $10 \mu \mathrm{g} . / \mathrm{ml}$. sterilized cultures of these isolates in $18 \mathrm{hr}$. at room temperature. The other antibiotics listed above had no microbicidal effect. On nutrient agar with glucose, the growth of the two cultures (no. 1804, 1806) was inhibited by isoniazid at $10 \mu \mathrm{g} . / \mathrm{ml}$. and by neomycin at $1 \mu \mathrm{g} . / \mathrm{ml}$.

Source. The two strains of Micropolyspora brevicatena were isolated from the sputa of two adult white males who had been treated for tuberculosis, but who did not have active tuberculosis at the time the sputa were collected. Isolate 1085 was isolated from the sputum of a white adult female who had no active tuberculosis but whose husband had.

Pathogenicity. Intravenous and subcutaneous injections with heavy suspensions of isolates $\mathbf{1 0 8 4}$ and $\mathbf{1 0 8 5}$ in white mice produced no apparent ill effect. After $\mathbf{1 5}$ days, the animals were sacrificed and examined for evidence of pathological changes. Spleens in the inoculated animals were slightly larger than those of the controls. All other organs appeared normal. Microscopic examination of the organs of the animals did not reveal any specific lesions. Guinea-pigs injected intraperitoneally with heavy suspensions of isolate 1084 were unaffected as far as could be seen from the examination of the growth curves over a period of $\mathbf{3 0}$ days and gross examination of organs 30 days after injection of the culture suspensions.

\section{DISCUSSION}

As pointed out previously, in Waksman's classification of actinomycetes the basic difference between the two families Actinomycetaceae and Streptomycetaceae is based on the assumption that the substrate mycelium of members of the Actinomycetaceae fragments into bacillary or coccoid elements, whereas the substrate mycelium of the members of Streptomycetaceae remains unfragmented. It is very doubtful whether such a system is sound, since variation in fragmentation can be observed between isolates obtained from the same strain of organisms presently called Nocardia and Streptomyces.

The fact that the distinction between the two families is unsound is further demonstrated by the organism here described. Micropolyspora fragments like Actinomycetaceae, and sporulates like Streptomycetaceae by forming chains of conidia on aerial hyphae. In addition it has a novel mode of sporulation, namely, the formation of chains of conidia on the substrate mycelium. These conidia are located in and on agar media. It would be most unwise to solve the dilemma by creating a new family to accommodate the genus Micropolyspora; instead, it is suggested that the name Streptomycetaceae be dropped and that the family Actinomycetaceae be enlarged as follows.

Family Actinomycetaceae Buchanan, 1918: Branching hyphae about $1 \mu$ in diameter form a substrate mycelium composed of hyphae, growing in and on agar media and an aerial mycelium formed of hyphae growing away from agar media. The aerial mycelium is sometimes lacking. The mycelium may or may not fragment into short segments which are either coccoid or rod-shaped. Mycelium may form single conidia or chains of conidia. Spores not formed in sporangia.

The following key to the genera of the Actinomycetaceae is proposed:

I. Anaerobic, or microaerophilic, organisms forming no conidia

1. Actinomyces Harz 
II. Aerobic organisms. Might form conidia singly or in chains.

A. Conidia formed singly

1. No aerial mycelium

2. Aerial mycelium formed

B. Conidia formed in longitudinal pairs on the aerial mycelium

4. Waksmania Lechevalier \& Lechevalier

c. Conidia formed singly and in chains on the substrate and on the aerial mycelium 5. Micropolyspora Lechevalier, Solotorovsky \& McDurmont

D. Conidia when formed are in chains on the aerial mycelium only
1. Mycelium fragmenting, conidia not always formed
6. Nocardia Trevisan
2. Mycelium non-fragmenting, conidia always formed

7. Streptomyces Waksman \& Henrici

Fragmentation should not be confused with septation. Septa can be observed in the mycelium of some actinomycetes which do not have any tendency to fragment.

In the proposed key, attention has been paid mainly to morphological differences based on the types of conidia formed. It seems hardly proper to put morphologically similar organisms in different genera because one organism is mesophilic and the other thermophilic.

The distinction between Nocardia and Streptomyces is simple in certain cases. A typical Streptomyces sp. which formed a non-segmenting substrate mycelium and a well-developed aerial mycelium bearing chains of conidia is easily distinguished from an organism which forms a fragmenting substrate mycelium with poorly developed aerial hyphae which do not bear any conidia. Frequently, however, the distinction is hard to make, as shown by some recently published papers (Gordon \& Mihm, 1958, 1961; Bradley, 1959).

In any event, Micropolyspora brevicatena represents a novel morphological type easily distinguishable from the previously described types that we have found in the literature and from those that we have studied up to now. One should note, however, that a thermophilic organism was described by Henssen (1957), under the name Pseudonocardia thermophila, which presumably forms chains of spores both on the substrate and aerial mycelium. The substrate mycelium of Pseudonocardia is septate and the chains of spores of this thermophilic organism seem to be fragments of the mycelium, quite different from the Waksmania-like conidia of Micropolyspora. Henssen's Pseudonocardia thermophila, judged on the basis of her description and photographs, seems to be a facultatively thermophilic Nocardia. We have examined two strains of Pseudonocardia thermophila (nos. 1179 and 1180) originally isolated by Henssen. We were unable to observe chains of conidia on the substrate mycelium.

A study of the ecology of strains of Micropolyspora would be of great interest. Such organisms have not been observed in soil. One might wonder if such organisms are to be found in healthy humans and animals, or, strangely, only in patients who have recovered from tuberculosis.

The authors wish to acknowledge the valuable advice and suggestions of Dr Ruth E. Gordon, and the technical assistance of Mrs Eva M. Fekete. The authors also wish to thank Miss Pauline E. Holbert for the electron micrographs. This work was supported in part by grant G-9694 from the National Science Foundation. 


\section{REFERENCES}

American Public Health Association Inc. (1950). Diagnostic Procedures and Reagents, 3rd ed. New York.

Bergey's Manual of Determinative Bacteriology (1957), 7th ed. Ed. by R. S. Breed, E. G. D. Murray \& N. R. Smith. Baltimore: The Williams and Wilkins Co.

Bradley, S. G. (1959). Sporulation by some strains of nocardiae and streptomycetes. Appl. Microbiol. 7, 89.

Conn, H. J., Darrow, M. A. \& Emmel, V. M. (1960). Staining Procedures used by the Biological Stain Commission, 2nd ed. Baltimore: The Williams and Wilkins Co.

Difco Manual of Dehydrated Culture and Reagents for Microbiological and Clinical Laboratory Procedures (1953), 9th ed. Detroit: Difco Laboratories.

Fred, E. B. \& Waksman, S. A. (1928). Laboratory Manual of General Microbiology. New York: McGraw-Hill Book Co. Inc.

Gondon, R. E. \& Mrнm, J. M. (1958). Sporulation by two strains of Nocardia asteroides. J. Bact. 75, 239.

Gondon, R. E. \& Minm, J. M. (1961). The type species of the genus Nocardia. J. gen. Microbiol. 24 (in the Press).

Henssen, A. (1957). Beiträge zur Morphologie und Systematik der thermophilen Actinomyceten. Arch. Mikrobiol. 26, 373.

Langeron, M. \& Vanbreuseghem, R. (1952). Précis de Mycologie. Paris: Masson et Cie.

Lechevalier, M. P. \& Lechevalier, H. (1957). A new genus of Actinomycetales Waksmania gen. nov. J. gen. Microbiol. 17, 104.

Nonomura, H. \& Ohara, Y. (1957). Distribution of actinomycetes in the soil. II. Microbispora, a new genus of Streptomycetaceae. J. fermen. Tech. 35, 307.

SÉguy, E. (1936). Code Universel des Couleurs. Paris: P. Lechevalier.

TARSHIS, M. S. (1953). Blood mediums for cultivation of Mycobacterium tuberculosis. V. Results with agar-agar basal medium and varying concentrations of blood, glycerine and penicillin. Amer. J. clin. Path. 23, 661.

Waksman, S. A. (1950). The Actinomycetes-their Nature, Occurrence, Activities, and Importance. Waltham, Mass.: Chronica Botanica Co.

\section{EXPLANATION OF PLATE 1}

Fig. 1. Isolate 1086 ; chains of spores on the surface of the agar (NZ amine glycerol agar, 6-day culture). $\times 660$.

Fig. 2. Isolate 1804; chains of spores on the surface of the agar (yeast-extract agar, 3-week culture). $\times 730$.

Fig. 3. Isolate 1084; chain of spores deep in the agar (soil-extract glycerol agar, 20-day culture). $\times 670$.

Fig. 4. Isolate 1086; chains of spores and globose structure on aerial hyphae (defined medium, 6-day culture). $\times 670$.

Fig. 5. Isolate 1084; chains of spores on aerial hyphae (soil-extract glycerol agar, 20-day culture). $\times 2000$.

Fig. 6. Isolate 1086; electron microphotograph of a chain of spores, with a branched sporophore. $\times 10,000$.

Fig. 7. Isolate 1086; electron micrograph of a chain of spores. $\times 10,000$.

Fig. 8. Isolate 1085; smear showing chains of spores. Gram stain. $\times 600$.

Fig. 9. Isolate 1086; stolon-like aerial hyphae (NZ-amine glycerol agar, 2-day culture). $\times 800$.

Fig. 10. Isolate 1084; 4-day culture on nutrient agar with glycerol. $\times 800$.

Fig. 11. Same culture $7 \mathrm{hr}$. later. Note formation of spores. $\times 800$. 


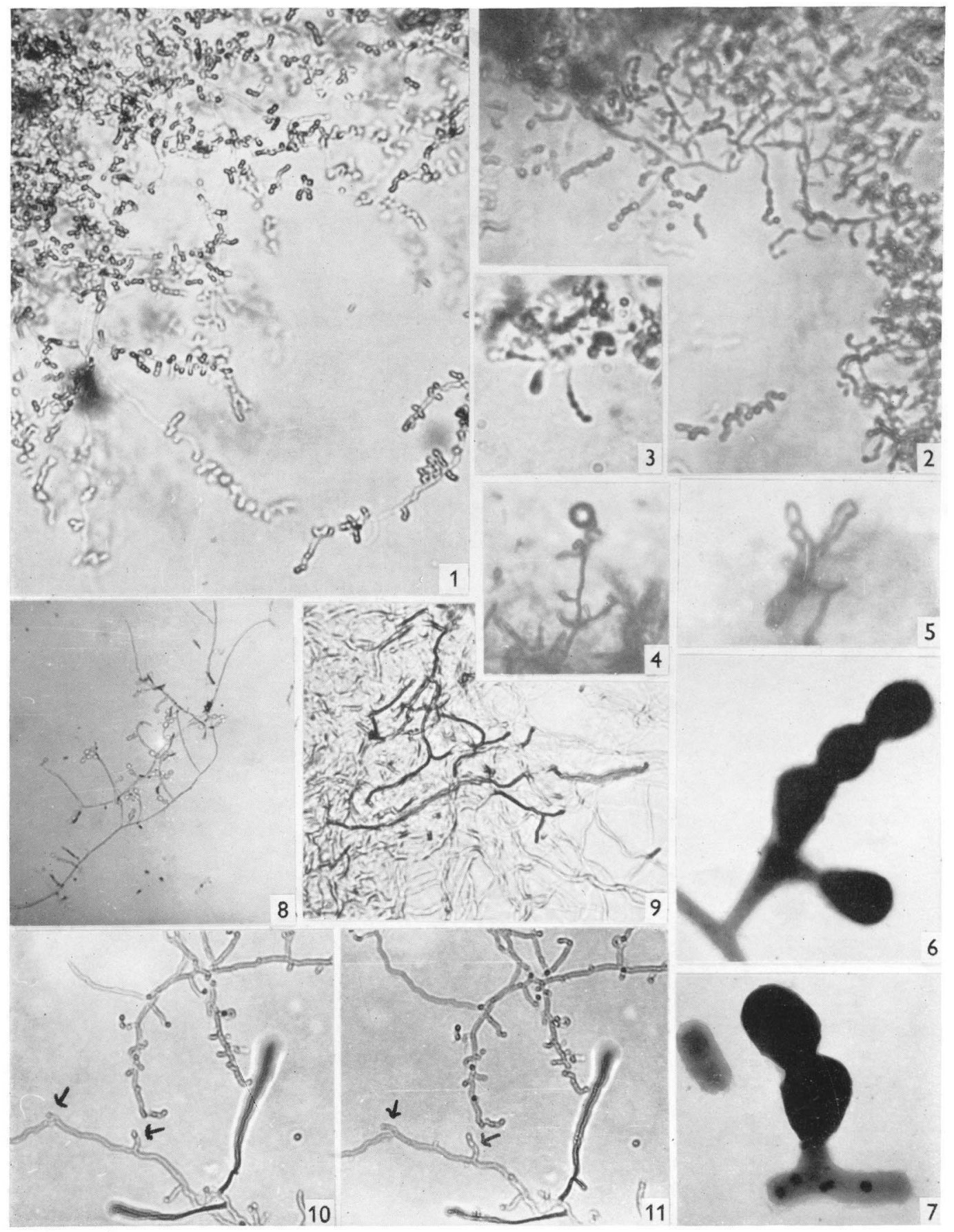

H. A. LECHEVALIER, M. SOLO'TOROVSKY AND C. I. McDURMON'T 